J. clin. Path., 22, suppl. (Ass. clin. Path.), 2, 66-71

\title{
Intermediary carbohydrate metabolism
}

\author{
P. J. RANDLE
}

From the Department of Biochemistry, University of Bristol

Current interest in mammalian carbohydrate metabolism is largely centred on the operation of metabolic pathways in tissues and whole animals. Recent studies have indicated that the various pathways may be controlled by one or two key enzymes which function as pacemakers. Transporting systems in the plasma membrane and also in intracellular membranes, such as the mitochondrial membrane, are of increasing importance in control and hence in the operation of metabolic pathways.

\section{CONTROL IN TISSUES}

The majority of enzymes and transporting systems in carbohydrate metabolism probably conform to Michaelis-Menten kinetics. The relationship between substrate concentration (or gradient) and reaction (or transport) velocity is hyperbolic, and velocity is also directly proportional to enzyme concentration. In terms of pathway operation reaction velocity (flow) is most sensitive to substrate concentration at values below the $K_{m},{ }^{1}$ and capacity, ie, $V_{\max ^{2}}$ or maximum flow, is mainly dependent upon enzyme or carrier concentration. Some enzymes do not conform to Michaelis-Menten kinetics and of particular interest from the point of view of control are those enzymes which exhibit sigmoid rate curves, ie, show a sigmoid relationship between reaction velocity and substrate concentration. From the point of view of pathway operation these enzymes have a threshold, and reaction velocity (or flow) is most sensitive to substrate concentration at values above the threshold and below the $K_{m}$. Enzymes which show sigmoid rate curves appear invariably to be regulatory enzymes, though there are some regulatory enzymes which show hyperbolic rate curves.

Although substrate concentration may be an important determinant of rate for some regulatory enzymes the concentration of effectors is of more general importance. Such effectors are metabolites which activate or inhibit enzymes for which they may or may not be substrates. Inhibitory effectors

${ }^{1}$ Michaelis constant, ie, substrate concentration at which reaction velocity $=$ half maximum velocity. ED.

${ }^{2} V_{\max }=$ maximum velocity of an enzyme reaction. may act by raising substrate $K_{m}$ or lowering $V_{\max }$ or both. They may conform to classical inhibitor kinetics (see Dixon and Webb. 1958) or the relationship between degree of inhibition and inhibitor concentration may be sigmoid (ie, show a threshold). Similar considerations may be applied to activators. In general it is important to distinguish between those inhibitors which influence $V_{\max }$ alone, $K_{m}$ alone, and both $V_{\max }$ and $K_{m}$. Where only $K_{m}$ is altered inhibition may be overcome by compensatory changes in substrate concentration; this will not be the case when only $V_{\max }$ is altered.

The identification of pacemaker reactions in metabolic pathways has depended upon simultaneous measurements of rates of flow and concentrations of substrates and products of individual reactions in tissues. The concepts of mass action ratios and of crossover have been particularly valuable. ${ }^{3} \mathrm{~A}$ pacemaker reaction is rate-limiting in its pathway and an increase in flow is due in particular to an increase in the activity of a pace-? maker enzyme. It follows that a pacemaker reaction must be displaced from equilibrium, under conditions where it limits flow in the whole pathway, ie, the mass action ratio of products and reactant will differ markedly from the equilibrium constant for the reaction. It is important to know whether the equilibrium constant is dependent on factors such as $p H$ (as in the case of kinases), or divalent ions (as in the case of aconitase), in interpreting mass action ratios. In the case of transport processes the mass action ratio is given by the ratio of concentrations on the two sides of the membrane; and the equilibrium constant is given by the ratio of concentrations at equilibrium. In general when flow through a pathway is increased by activation of a pacemaker reaction, the mass action ratio is changed in the direction of the equilibrium constant. The identification of a pacemaker reaction may be most clearly made when a crossover occurs, $i e$ when for a particular reaction in a metabolic pathway an increased rate of flow is accompanied by a decrease in substrate concentration(s) and an increase in product concentration(s) or vice versa. Unfortunately there are instances where no clear crossover 'See Editors' Appendix. 
occurs although an increase in mass action ratio may accompany an increase in flow. This may be seen, for example, when two or more pacemaker reactions are in close apposition.

An additional and necessary approach involves screening individual enzymes for activation or inhibition by a wide variety of metabolites. This type of study can indicate possible regulatory enzymes and suggest whole tissue experiments to establish their regulatory role. It has been particularly valuable in situations where two or more regulatory enzymes are closely apposed in metabolic pathways. The elucidation of mechanisms of regulation is similarly dependent upon the detection of effectors for individual enzymes and the demonstration of effector mechanisms in the cell.

Studies along these lines have indicated probable control mechanisms for a number of pathways of carbohydrate metabolism and have provided a qualitative basis for understanding their operation. Fuller understanding can come only from quantitative studies in which the operation of the pathway may be described in the form of mathematical models based on the kinetic properties and concentrations of enzymes together with the concentrations of their substrates and effectors. Some progress along these lines is now being made in restricted segments of pathways but this approach raises special problems. Enzyme kinetics have mostly been derived from studies with enzymes in dilute solution where substrate or effector concentrations are in vast excess. In cells the concentrations of some enzymes may be comparable to that of their substrates or effectors and it is not known whether this will appreciably modify their kinetic properties.

The control of glycolysis in muscle is discussed in a later section as an illustration of these techniques and problems.

\section{CONTROL IN ANIMALS: METABOLIC INTEGRATION}

The control mechanisms which have been outlined for tissues are mechanisms common to both unicellular organisms and to individual cells of animals. Additional control mechanisms are seen in animals which lead to integration of the varied metabolic pathways of individual tissues. These control mechanisms are partly a consequence of metabolic specialization (for example gluconeogenesis in liver and lipid synthesis and breakdown in adipose tissue); and partly a consequence of the relatively small circulating pools of metabolites. The plasma free fatty acid pool, for example, may turn over in three to five minutes; that of glucose in 30 to 60 minutes. The pools are thus small in relation to feeding habits.
Metabolic integration may involve both receptor and effector systems and is mediated in part by the endocrine system and in part by the nervous system. The secretion of insulin is regulated in the $\beta$-cell by the blood glucose concentration. In this instance the receptor system lies within the cell secreting the effector (insulin). The secretion of pituitary growth hormone may also depend upon blood glucose concentration but in this instance the receptor cells may be located in the hypothalamus. Some consideration is given in a later section to the glucoreceptor mechanism in the pancreas.

\section{CONTROL OF GLYCOLYSIS IN MUSCLE}

Table I shows the enzymes and transport systems concerned with glucose uptake, glycolysis, glycogen synthesis, glycogenolysis, and pyruvate oxidation in muscle. Glucose uptake appears to be controlled by the two apposed steps of plasma membrane transport of glucose and its intracellular phosphorylation by hexokinase. The glycolytic pathway between glucose 6-phosphate and pyruvate appears to be controlled only by phosphofructokinase. Glycogen synthesis may be regulated by glycogen synthetase and glycogen breakdown by phosphorylase. The entry of glucose into the citrate cycle may be regulated by pyruvate dehydrogenase.

The control systems appear to subserve three major physiological roles. One set of signals may vary rates of glucose uptake, glycogen breakdown, and glycolysis according to the state of ATP synthesis and breakdown. Thus glucose transport, phosphorylase $b$, and phosphofructokinase may be activated by breakdown products of ATP (ADP, AMP, and phosphate) and inhibited by ATP. Another set of signals may regulate rates of glucose uptake, glycogen synthesis and breakdown, glycolysis and pyruvate oxidation according to the availability of alternative respiratory fuels such as fatty acids or ketone bodies. The major signals appear to be acetyl CoA, CoA, $\mathrm{NADH}_{2}$, and NAD which may regulate pyruvate dehydrogenase, and citrate formed from acetyl $\mathrm{CoA}$ which may regulate phosphofructokinase. A third mechanism is concerned with hormone action. Insulin may stimulate glucose uptake by activating glucose transport and stimulate glycogen formation by causing the conversion of glycogen synthetase from $D$ to I form. In its $D$ form the activity of glycogen synthetase is critically dependent upon glucose 6-phosphate concentration. The $I$ form is independent of glucose 6-phosphate. In this regard the action of insulin may be visualized as causing an enzyme conversion which enables glycogen synthesis to be independent of intracellular signals (in this case glucose 6- 
TABLE I

ENZYME ACTIVITIES IN MOUSE ISLETS WHICH MAY REGULATE RATES OF GLUCOSE PHOSPHORYLATION

\begin{tabular}{|c|c|c|c|}
\hline Pathway Segment & Enzyme (or Carrier) & Activator & Inhibitor \\
\hline \multirow[t]{2}{*}{ Glucose uptake } & Glucose transport & $\begin{array}{l}\text { Insulin } \\
\text { ?AMP }\end{array}$ & ?ATP \\
\hline & Hexokinase & & $\begin{array}{l}\text { Glucose 6-phosphate } \\
\text { AMP, ADP. }\end{array}$ \\
\hline \multirow[t]{2}{*}{ Glycolysis } & $\begin{array}{l}\text { Phosphoglucoisomerase } \\
\text { Phosphoglucomutase } \\
\text { Phosphofructokinase }\end{array}$ & $\begin{array}{l}\qquad-\overline{-} \\
\text { AMP, ADP } \\
\text { Phosphate } \\
\text { Fructose 6-phosphate } \\
\text { Fructose 1:6-diphosphate } \\
\text { Sulphate } \\
\text { Cyclic 3'5'-AMP }\end{array}$ & $\underset{\text { Citrate }}{\text { ATP }}$ \\
\hline & $\begin{array}{l}\text { Aldolase } \\
\text { Triose phosphate isomerase } \\
\text { Triose phosphate dehydrogenase } \\
\text { Phosphoglyceromitase } \\
\text { Enolase } \\
\text { Pyruvate kinase } \\
\text { Lactate dehydrogenase } \\
\text { Glycerolphosphate dehydrogenase }\end{array}$ & $\begin{array}{l}- \\
= \\
= \\
=\end{array}$ & $\begin{array}{l}- \\
- \\
- \\
-\end{array}$ \\
\hline \multirow{2}{*}{$\begin{array}{l}\text { Glycogen } \\
\text { synthesis }\end{array}$} & UDP glucose pyrophosphorylase & - & \\
\hline & $\begin{array}{l}\text { Glycogen synthetase (D form) } \\
\text { Glycogen synthetase (I form) } \\
\text { Branching enzyme }\end{array}$ & $\begin{array}{c}\text { Glucose 6-phosphate } \\
\text { - }\end{array}$ & $\begin{array}{r}\text { Glycogen } \\
-\end{array}$ \\
\hline \multirow[t]{2}{*}{ Glycogenolysis } & Phosphorylase $b$ & AMP & $\begin{array}{l}\text { ATP } \\
\text { Glucose 6-phosphate } \\
\text { Malate }\end{array}$ \\
\hline & $\begin{array}{l}\text { Phosphorylase } a \\
\alpha-1: 6-\text { Amyloglycosidase }\end{array}$ & 二 & $\overline{-}$ \\
\hline $\begin{array}{l}\text { Aerobic } \\
\text { oxidations }\end{array}$ & Pyruvate dehydrogenase & $\begin{array}{l}\text { CoA } \\
\text { NAD }\end{array}$ & $\begin{array}{l}\text { Acetyl CoA } \\
\text { NADH }_{2}\end{array}$ \\
\hline $\begin{array}{l}\text { Regulation of } \\
\text { phosphofructokinase }\end{array}$ & $\begin{array}{l}\text { Citrate transport } \\
\text { (mitochondrial membrane }\end{array}$ & Malate & - \\
\hline
\end{tabular}

by citrate

phosphate). Similarly the action of adrenaline in causing glycogen breakdown appears to involve the conversion of phosphorylase from the $b$ form, requiring activation by AMP and inhibited by ATP and glucose 6-phosphate, to the $a$ form which is not dependent upon AMP for activity and which is largely insensitive to effectors (AMP, ATP or glucose 6-phosphate).

In terms of operation glucose uptake, glycogen synthesis and breakdown and glycolysis may function as a single complex unit. For example, glycolytic fiux is dependent upon glucose uptake or glycogen breakdown or a combination of the two. More detailed examination of the control of hexokinase, glycogen synthetase (D form), phosphorylase $b$, and phosphofructokinase suggests that they may act as a single complex unit. The connecting link appears to be the concentrations of glucose 6-phosphate and fructose 6-phosphate which are held in equilibrium by phosphoglucoisomerase. Glucose 6-phosphate may inhibit hexokinase and phosphorylase $b$ and activate glycogen synthetase (D form); and fructose 6-phosphate may activate phosphofructokinase. The effects of glucose 6-phosphate are on the $V_{\max }$ of the three enzymes concerned. This may be especially important with hexokinase where inhibition by glucose 6-phosphate may increase the intracellular glucose concentration. Because the inhibition by glucose 6-phosphate affects $V_{\max }$ and not $K_{m}$ there may be little or no compensatory increase in the rate of glucose phosphorylation when glucose accumulates. The control of phosphofructokinase, on the other hand, appears to be through effects on the $K_{m}$ for fructose 6-phosphate. The enzyme is inhibited by ATP which raises the $K_{m}$ for fructose 6-phosphate and this inhibition is overcome by fructose 6phosphate. Rate curves for fructose 6-phosphate are thus sigmoid, because fructose 6-phosphate is both substrate and activator, and the $K_{m}$ is dependent on ATP concentration. Citrate increases the ATP inhibition and further raises the $K_{m}$. Phosphate, ADP and AMP, and fructose 1:6-diphosphate 
reverse ATP inhibition and lower the $K_{m}$ for fructose 6-phosphate.

The operation of this complex has been deduced from studies of the effects of anoxia, of fatty acids and ketone bodies, and of insulin in rat heart muscle. Anoxia accelerates glycolysis, glucose phosphorylation, and glycogen breakdown and leads to a crossover between substrates and products of the phosphofructokinase reaction (ATP and fructose 6-phosphate decrease; ADP and fructose 1:6diphosphate increase). Lack of oxygen is believed to lower ATP and raise ADP, AMP, and phosphate and thus activate phosphofructokinase and phosphorylase $b$. Activation of phosphofructokinase raises fructose 1:6-diphosphate (producing a further activation) and lowers fructose 6-phosphate and glucose 6-phosphate. The change in glucose 6phosphate may then activate hexokinase and also phosphorylase $b$. Fatty acids or ketone bodies inhibit glycolysis and glucose phosphorylation and stimulate glycogen synthesis and lead to a crossover between substrates and products for phosphofructokinase (fructose 6-phosphate increases and fructose 1:6-diphosphate decreases; ATP and ADP are little changed). They act by increasing citrate concentration thereby inhibiting phosphofructokinase and leading to accumulation of glucose 6phosphate, inhibition of hexokinase and phosphorylase $b$, and possibly activation of glycogen synthetase (D form). Insulin accelerates glucose uptake, glycolysis, and glycogen synthesis and leads to a crossover at the glucose transport step (intracellular glucose concentration is increased from an extremely low value). Insulin is thus thought to accelerate glucose transport and as a consequence to increase intracellular glucose concentration and thus promote glucose phosphorylation. The increased rate of glycolysis may be due to an increase in fructose 6-phosphate concentration activating phosphofructokinase.

This system has yet to be evaluated quantitatively as a whole. However, a quantitative evaluation of the control of hexokinase predicted from the kinetic properties of the enzyme has been shown to be valid in the perfused rat heart (England and Randle, 1967).

One of the problems to be surmounted in an analysis of the whole system is the effect of compartmentation. In heart muscle citrate synthesis may be confined to the mitochondrion whereas citrate inhibition of phosphofructokinase is cytoplasmic. The regulation may thus involve export of mitochondrial citrate for which there appears to be a citrate transporting system requiring activation by malate (Chappell, Henderson, McGivan, and Robinson, 1968; England and Robinson, 1969).

\section{PANCREATIC $\beta$-CELL GLUCORECEPTOR}

The secretion of insulin by pancreatic $\beta$-cells is stimulated by glucose. The rate curve for secretion at varying glucose concentration measured with rat pancreas in vitro is sigmoid with a threshold at approximately $90 \mathrm{mg} / 100 \mathrm{ml}$ and with a $K_{m}$ of approximately $180 \mathrm{mg} / 100 \mathrm{ml}$ (Malaisse, MalaisseLagae, and Wright, 1967). Several lines of evidence have indicated that the effect of glucose on insulin secretion is transmitted through metabolism of the sugar in the $\beta$-cell. Secretion is stimulated only by those sugars which can be readily metabolized (glucose and mannose). There is a close correlation between rates of glucose oxidation and effects on secretion. Rate curves for glucose oxidation by mouse islets at 'varying glucose concentration are also sigmoid with a threshold at $90 \mathrm{mg} / 100 \mathrm{ml}$, and with a $K_{m}$ of approximately $130 \mathrm{mg} / 100 \mathrm{ml}$. Glucose oxidation is suppressed by mannoheptulose which also suppresses the glucose effect on secretion, whereas phloridzin has no effect either on secretion or on glucose oxidation. As a working hypothesis it has been suggested that the metabolism of glucose in the islet cell alters the concentration of some metabolite of glucose which activates the secretory process. The glucoreceptor has thus been visualized as an enzyme or transport system involved in the initiation of glucose metabolism. Glucose transport systems in other cells and tissues are inhibited by phloridzin. Mannoheptulose on the other hand appears to be an inhibitor of hexokinases and glucokinase and moreover it can penetrate only those cells, eg, liver, which are freely permeable to glucose, ie, cells in which phosphorylation of glucose is the first step in its metabolism. Since in the islet mannoheptulose is inhibitory whereas phloridzin is not, it has been suggested that the glucoreceptor is an enzyme or enzymes regulating glucose phosphorylation. The properties of the glucoreceptor must be capable of explaining the sigmoid rate curve for insulin secretion and for glucose oxidation with a threshold of approximately $90 \mathrm{mg} / 100 \mathrm{ml}$ and a $K_{m}$ of approximately 130 to $180 \mathrm{mg} / 100 \mathrm{ml}$; and of explaining the powerful inhibitory effect of mannoheptulose.

Three enzyme activities have been detected in homogenates of mouse islets which may contribute to the overall rate of glucose phosphorylation in this tissue by Matschinsky and Ellerman (islets of obese, hyperglycaemic mice) and Ashcroft and Randle (islets of normal mice). Table II summarizes kinetic data published by Randle and Ashcroft (1969). Two enzymes phosphorylating glucose have been detected. One is a hexokinase with a low $K_{m}$ for glucose, $1.3 \mathrm{mg} / 100 \mathrm{ml}$, and inhibited non- 
TABLE II

\begin{tabular}{|c|c|c|c|c|}
\hline Enzyme Activity & $K_{m}(m M)$ & ENZ & $\begin{array}{l}\text { OF GLYCOLYSIS } \\
V_{\max }^{3.70}(\text { units } / g)\end{array}$ & $\begin{array}{l}\text { ULATION } \\
\text { Inhibitors } K_{\mathfrak{i}}(m M)^{1}\end{array}$ \\
\hline Hexokinase & $\begin{array}{l}\text { Glucose } \\
\text { ATP }\end{array}$ & $\begin{array}{l}0.075 \\
0 \cdot 77\end{array}$ & 0.54 & $\begin{array}{ll}\text { Glucose 6-phosphate } 0.22 \\
\text { Mannoheptulose } \quad 0.25\end{array}$ \\
\hline Glucokinase & Glucose & 22 & $0 \cdot 17$ & $\begin{array}{l}\text { Mannoheptulose ( } K_{i} \text { not known but inhibition } \\
\text { weak) }\end{array}$ \\
\hline Glucose 6-phosphatase & $\begin{array}{l}\text { Glucose 6- } \\
\text { phosphate }\end{array}$ & $1 \cdot 0$ & $0 \cdot 70$ & $\begin{array}{l}\text { Glucose mixed inhibition } K_{1} 9 K_{2} 38 \text {. Not reversed } \\
\text { by mannoheptulose }\end{array}$ \\
\hline
\end{tabular}

competitively by glucose 6-phosphate and competitively by mannoheptulose. The other, provisionally designated as glucokinase, has a high $K_{m}$ for glucose, $396 \mathrm{mg} / 100 \mathrm{ml}$; it is not inhibited by glucose 6-phosphate and may be activated by it; it is weakly inhibited by mannoheptulose. Glucose 6-phosphatase activity is a'so present and it is inhibited by glucose, but not by mannose. Glucose inhibits by raising $K_{m}$ as well as lowering $V_{\max }$, and 50 per cent inhibition is seen at approximately $180 \mathrm{mg} / 100 \mathrm{ml}$.

Although the properties of these enzymes may ultimately account for the glucoreceptor mechanism there are a number of unexplained facts which make it difficult to compound any satisfactory model. Rate curves with each of the enzymes are hyperbolic whereas rate curves for insulin secretion and glucose oxidation in the islet are sigmoid. Moreover the kinetics of mannoheptulose inhibition of hexokinase are such as to be incapable of explaining the inhibitory effect of mannoheptulose on glucose oxidation in the islet, with the glucose $K_{m}$ value obtained. The inhibition of glucokinase by mannoheptulose is too weak to explain its effect in the islet. A sigmoid rate curve may be achieved by a combination of glucose 6-phosphatase and hexokinase and taking into account inhibitory effects of glucose and glucose 6-phosphate. However such a combination may not explain the effects of mannose on insulin release and mannose oxidation, because mannose is not an inhibitor of the glucose 6-phosphatase. A more complete evaluation taking into account, for example, the possibility of activation of glucokinase by glucose 6-phosphate is required.

\section{CLINICAL APPLICATIONS OF CONTROL MECHANISMS}

The importance of inherited defects in the catalytic activities of enzymes in the aetiology of some diseases has been recognized for nearly half a century following Garrod's description of inborn errors of metabolism. Studies of control mechanisms have in effect added a new dimension to enzymology since they have shown that enzymes have regulatory as well as catalytic activity. It is not unreasonable to expect that future investigation will reveal inborn errors which affect the regulatory activities of enzymes and not their catalytic activities. Similarly the realization of the role of plasma membrane and intracellular membrane transporting systems in metabolic pathways and metabolic regulation suggests the basis for new investigation of metabolic disease. The specificity of some enzyme regulations and some transporting systems in the operation of metabolic pathways indicates the possibility of new drugs. For example, in diabetes due to insulin deficiency many of the changes in the carbohydrate metabolism of muscle, which may lead to insuliro unresponsiveness, are similar to the changes pro duced by oxidation of fatty acids. Some of thesechanges have been referred to in the section on+ glycolysis. It has been suggested that these changes in diabetic muscle are in fact due to accelerated triglyceride breakdown and fatty acid oxidation. If this is so then inhibitors of fatty acid oxidation should reverse the abnormalities of carbohydrate metabolism in diabetic muscle. Some evidence for this possibility has been achieved in studies with 2-bromo fatty acids (palmitate or stearate) which can inhibit specifically carnitine acyl transferase in the pathway of fatty acid oxidation. Experiments in vitro with rat heart muscle have indicated that 2-bromostearate can reverse abnormalities of glucose uptake, glucose phosphorylation, glycolysis, and glucose oxidation due to inhibition of hexokinase, phosphofructokinase, and pyruvate dehydrogenase in alloxan diabetes (Burges, Butt, and Baggaley, 1968; Randle, 1969).

\section{REFERENCES}

Burges, R. A., Butt, W. D., and Baggaley, A. (1968). Biochem. J., 109, 38P.

Chappell, J. B., Henderson, P. J. F., McGivan, J. D., and Robinson, B. H. (1968). In The interaction of Drugs and Subcellular Components, Edited by P. N. Campbell, p. 71. Churchill, London.

Dixon, M., and Webb, E. C. (1958). Enzymes. Longmans Green, London.

England, P. J., and Randle, P. J. (1967). Biochem. J., 105, 907. , and Robinson, B. H. (1969). Ibid., 112, 8P. 
Malaisse, W., Malaisse-Lagae, F., and Wright, P. H. (1967). Endocrinology, 80, 99.

Randle, P. J. (1969). Nature (Lond.), 221, 777.

, and Ashcroft, S. J. H. (1969). Biochem. J., 12, IP.

\section{EDITORS' APPENDIX}

The mass action ratio is the concentration of the product of an enzyme reaction divided by the concentration of the substrate. The velocity of an enzyme reaction increases with substrate concentration and decreases with product concentration, so that the reaction velocity is inversely proportional to the mass action ratio. When the reaction is at equilibrium, $i e$, when the reaction velocity is zero, the mass action ratio will be at its maximum and equal to the equilibrium constant of the enzyme.

When the rate of flow along a metabolic pathway is below its maximum because it is restricted by a rate-limiting 'pacemaker' reaction controlled by a regulatory enzyme, all the other enzymes of the pathway will be running well below their capacity and hence their mass action ratios will be relatively high and close to the equilibrium constant. The rate-limiting reaction, however, will be running at its full (but limited) capacity, so that its mass action ratio will be low and considerably displaced from the equilibrium constant, often by several orders of magnitude.

Acceleration of flow along the pathway is achieved by an increase in the capacity of the regulatory enzyme, and the resulting increase in activity causes a fall in the enzyme's substrate concentration and a rise in its product concentration so that the mass action ratio rises towards the equilibrium constant. The preceding reaction in the pathway is also accelerated because the concentration of this enzyme's product (which is the substrate of the regulatory enzyme) is now lower, resulting in a fall of the mass action ratio away from the equilibrium constant. The reaction which follows the pacemaker reaction is accelerated too because its substrate (which is the product of the regulatory enzyme) is now higher, again resulting in a fall of the mass action ratio away from the equilibrium constant. Hence activation of the pathway is associated with a rise, usually large, in the mass action ratio of the regulatory enzyme whereas there is a fall, usually small, in the mass action ratios of the other enzymes. This 'cross-over' of mass action ratios is one method of identifying the regulatory enzyme, another being the large displacement of its mass action ratio from the equilibrium constant and the extent of its change when the pathway is activated. 